\title{
Expression of S100 $\beta$ protein in patients with vascular dementia after basal ganglia hemorrhage and its clinical significance
}

\author{
SHUAITAO SHI, GUOQUAN WANG, KEWEI ZHANG, ZHIDONG ZHANG, KAI LIANG, \\ KUN LI, WEIXIAO LI and SHUITING ZHAI \\ Interventional Therapy Center, Henan Provincial People's Hospital, Zhengzhou, Henan 450003, P.R. China
}

Received July 29, 2016; Accepted February 2, 2017

DOI: $10.3892 /$ etm.2017.4207

\begin{abstract}
We investigated the expression levels and clinical significance of $\mathrm{S} 100 \beta$ protein in patients with vascular dementia (VD) after basal ganglia hemorrhage. From June 2014 to December 2015, in 138 patients with basal ganglia hemorrhage, we carried out the Mini-Mental State Examination (MMSE) and Montreal Cognitive Assessment (MoCA) in patients on the day before the operation, the day after the operation and 9 days after the operation. Thirty-two patients (blood vessel group) had cognitive dysfunction and 106 patients (control group) had VD. One hundred thirty-eight cases of healthy adult volunteers were treated in Henan Provincial People's Hospital and were selected in the same period as healthy controls. The expression levels of serum S100 $\beta$ in the three groups were tested through the ELISA method and the statistical analysis was carried out. In VD patients, the serum S100 $\beta$ levels of patients were significantly higher than VD and healthy control groups; differences were statistically significant $(\mathrm{P}<0.05)$. However, there was no significant difference between those without VD after operation and the healthy control group $(\mathrm{P}>0.05)$. The correlation analysis was carried out with serum S100 $\beta$ as an independent variable and mean arterial pressure, BMI, MMSE and MoCA scores as dependent variables. Our results suggest that $\mathrm{S} 100 \beta$ expression levels were negatively correlated to the MMSE score ( $\mathrm{rs}=-4.19)$ and the difference was statistically significant $(\mathrm{P}<0.05)$. The length of hospital stay of patients with basal ganglia hemorrhage associated with VD was significantly extended, with a mean of $23.4 \pm 2.8$ days. The expression levels of $S 100 \beta$ protein in the serum of patients with VD after basal ganglia hemorrhage was significantly
\end{abstract}

Correspondence to: Dr Shuiting Zhai, Interventional Therapy Center, Henan Provincial People's Hospital, 7 Weiwu Road Zhengzhou, Henan 450003, P.R. China

E-mail: zhuo_shuiting1@163.com

Key words: basal ganglia hemorrhage, $\mathrm{S} 100 \beta$ protein, vascular dementia increased and negatively correlated to the cognitive function of patients. Therefore, it can be used as a differential diagnosis indicator of VD after the basal ganglia hemorrhage and treatment target point of the VD.

\section{Introduction}

Vascular dementia (VD) refers to the severe cognitive dysfunction syndrome caused by the ischemic stroke, hemorrhagic stroke and cerebrovascular diseases that cause low perfusion in memory, cognition, behavior and other brain areas (1). Basal ganglia hemorrhage usually occurs in the putamen and thalamus and is usually caused by high blood pressure, which seriously affects patient's social life skills and quality of life after the cerebral hemorrhage recovery (2).

$\mathrm{S} 100 \beta$ protein is a type of protein in nerve tissue, and under normal circumstances, the expression levels of $\mathrm{S} 100 \beta$ protein are significantly increased (3) in both glial cells and Schwann cells. Under physiological conditions, its levels are very low in the serum. When the blood-brain barrier permeability is significantly increased due to damage to individual nerve cells or under various pathological conditions, the $\mathrm{S} 100 \beta$ protein levels in the serum are abnormally increased. In Alzheimer's patients, an increase in the levels of S100 $\beta$ in the serum can be observed (4). However, in patients with VD, the expression levels of $\mathrm{S} 100 \beta$ and its clinical significance are still unclear.

This study provides a theoretical basis for the development and research of targeted treatment drugs by testing the expression levels of $\mathrm{S} 100 \beta$ in the plasma of 138 patients with basal ganglia hemorrhage and 138 healthy patients in the control group. We analyzed the clinical significance of S100 $\beta$ levels of cognitive dysfunction patients before and after the treatment of the VD patients.

\section{Materials and methods}

Sample selection. One hundred thirty-eight patients, who were clinically diagnosed with and confirmed as basal ganglia hemorrhage through imaging diagnosis from June 2014 to December 2015, were selected for this study. The mean age of the patients was $54.5 \pm 12.7$ years. This study was approved 
by the Ethics Committee of Henan Provincial People's Hospital. Signed written informed consents were obtained from all participants before the study.

Inclusion criteria. i) Patients diagnosed with basal ganglia hemorrhage caused by high blood pressure; and ii) patients older than 18 years.

Exclusion criteria. i) Those who had been administered immunosuppressive agents; ii) patients with acute or chronic bacterial and/or viral infections; iii) patients with autoimmune diseases; iv) patients with connective tissue diseases; v) patients with malignancy; vi) patients with hepatic and renal dysfunction; vii) patients with chronic muscular diseases; viii) patients with peripheral vascular disease, chronic heart failure, thyroid disease, liver or kidney dysfunction, cancer and major trauma in nearly half of the year and a history of the surgery; ix) patients with diabetes mellitus; $x$ ) patients with the functional classification of New York Heart Association as class III and IV; and xi) patients with brain hemorrhage caused by brain trauma and other factors were excluded (2).

Diagnostic criteria. VD clinical diagnosis standard was developed according to the US National Institute of Neurological Disorders and Stroke-Association Internationale pour la Recherche et l'Enseignement en Neurosciences (NINDS-AIREN) (5).

Mini-Mental State Examination (MMSE) (6). One point was given for each correct answer, 0 for wrong or unknown, 9 points in total for discomfort and 8 points for refusal to answer or for not being able to understand. When calculating the total score, 8 and 9 points should be calculated as 0 . The highest score attainable is 30 points. The division of dementia is correlated to the education background and therefore, if the elderly were illiterate and scored lower than 17 points, graduated from primary school and scored lower than 20 points, graduated from secondary school or over and scored lower than 24 points, they would be given the diagnosis of dementia: 27-30, normal; 21-26, mild; 10-20, moderate; and $0-9$, severe.

Montreal Cognitive Assessment (MoCA) (7). The test include various tasks such as visual space executive capacity, naming, memory, attention, verbal fluency, abstract thinking, delayed memory and orientation for a total of 30 points. One point was added to the test results if the subjects' education years were lower than 12 years, and the education level bias was corrected; higher scores indicated better cognitive function of the subjects and 26 points indicated normal cognitive function.

Specimen collection. Elbow venous blood $(3 \mathrm{ml})$ was extracted on an empty stomach in the morning. The blood was injected into an ordinary plastic tube, $1.8 \mathrm{ml}$ of which was transferred into the anticoagulant tube (KeyGene Co., Nanjing, China) containing $0.2 \mathrm{ml} \mathrm{3.8 \%} \mathrm{sodium} \mathrm{citrate} \mathrm{and} \mathrm{centrifuged} \mathrm{for}$ $10 \mathrm{~min}$ at $2,500 \mathrm{xg}$ within $1 \mathrm{~h}$ after sample collection. The extracted serum or plasma was placed in $0.5 \mathrm{ml}$ Eppendorf (EP) tube (KeyGene Co.) respectively, stored at $-30^{\circ} \mathrm{C}$ and then tested within a month.
Table I. Comparison of baseline data of included patients.

\begin{tabular}{lcccc}
\hline Groups & $\begin{array}{c}\text { Case } \\
\text { nos. }\end{array}$ & $\begin{array}{c}\text { Age } \\
\text { (years) }\end{array}$ & $\begin{array}{c}\text { BMI } \\
\left(\mathrm{kg} / \mathrm{m}^{2}\right)\end{array}$ & $\begin{array}{c}\text { MAP } \\
(\mathrm{mmHg})\end{array}$ \\
\hline Patient case & 138 & $51.5 \pm 12.7$ & $20.7 \pm 1.2$ & $128.3 \pm 19.4$ \\
Healthy & 138 & $52.6 \pm 10.8$ & $19.7 \pm 1.3$ & $76.5 \pm 10.9$ \\
control & & & & \\
T-value & - & 0.33 & 1.49 & 31.33 \\
P-value & - & 0.47 & 0.12 & 0.02 \\
\hline
\end{tabular}

MAP, mean arterial pressure.

Measurement of expression levels of serum S100 $\beta$ through the enzyme-linked immunosorbent assay (ELISA) method. The ELISA test was used to test the expression levels of serum S100 $\beta$. All reagents used in this study were purchased from Wuhan Boster Bio-Engineering Co., Ltd. (Wuhan, China) and the operation was in full accordance with the operating instructions.

Treatment method. Patients were subjected to the blood pressure reduction treatment and supplemented by the control on vasogenic edema. In terms of the administration, anti-fibrinolytic drugs such as 6-amino acid, or tranexamic acid (Yangze Pharma, Taizhou, China) was administrated early ( $<3 \mathrm{~h})$.

Statistical analysis. All measurement data are expressed as mean \pm standard deviation (SD). SPSS 17.0 statistical software (SPSS, Inc., Chicago, IL, USA) was used for processing. The repeated measurement data analysis of variance (ANOVA) was applied for statistical analysis. The t-test of two independent samples was used for the measurement data among groups, the paired t-test was used for comparison between the groups, and the countable data were tested with $\chi^{2}$ test. $P<0.05$ was considered to indicate a statistically significant difference.

\section{Results}

Comparison of baseline data of the patients. We recorded and carried out statistical analysis on the age, weight, BMI and other baseline data of 138 patients with basal ganglia hemorrhage and 138 healthy patients in the control group; there were no statistical differences in baseline data for the patients included in the groups $(\mathrm{P}>0.05)$. However, the mean arterial pressure (MAP) levels of the patients in the case group were significantly higher than that in the control group $(\mathrm{P}<0.05)($ Table $\mathrm{I})$.

MMSE and MoCA scores of patients in each group. We administered the MMSE and MoCA on patients with basal ganglia hemorrhage included in the groups on one day before the operation, one day after the operation and in the first week after the operation. Thirty-two patients (blood vessel group) were diagnosed with cognitive dysfunction and 106 patients (control group) were not diagnosed with VD. The comparison of MMSE and MoCA scores of the patients between the two groups found that the MMSE and MoCA scores of the patients in the VD group 
Table II. MMSE and MoCA scores of patients in each group.

\begin{tabular}{|c|c|c|c|c|c|c|}
\hline Items & Groups & $\begin{array}{l}\text { Case } \\
\text { nos. }\end{array}$ & $\begin{array}{l}\text { First day after } \\
\text { the operation }\end{array}$ & $\begin{array}{l}\text { Second day after } \\
\text { the operation }\end{array}$ & $\begin{array}{l}\text { Ninth day after } \\
\text { the operation }\end{array}$ & P-value \\
\hline \multirow[t]{4}{*}{ MMSE } & VD & 32 & $28.3 \pm 1.6$ & $24.3 \pm 1.4$ & $21.3 \pm 3.2$ & 0.01 \\
\hline & Control & 106 & $29.2 \pm 1.7$ & $27.5 \pm 2.8$ & $28.4 \pm 2.2$ & 0.38 \\
\hline & T-value & - & 0.33 & 0.36 & 0.29 & - \\
\hline & P-value & - & 0.69 & 0.22 & 0.77 & - \\
\hline \multirow[t]{4}{*}{ MoCA } & VD & 32 & $29.6 \pm 0.4$ & $22.1 \pm 1.8$ & $21.4 \pm 1.3$ & 0.03 \\
\hline & Control & 106 & $28.7 \pm 1.5$ & $27.3 \pm 2.6$ & $28.3 \pm 0.8$ & 0.98 \\
\hline & T-value & - & 0.42 & 0.44 & 0.78 & - \\
\hline & P-value & - & 0.38 & 0.67 & 0.22 & - \\
\hline
\end{tabular}

MMSE, Mini-Mental State Examination; MoCA, Montreal Cognitive Assessment; VD, vascular dementia.

Table III. Measurement of expression level of the peripheral S100 $\beta$ levels of patients and those in the healthy control group through ELISA method $(\mathrm{ng} / \mu \mathrm{l})$.

\begin{tabular}{lccccc}
\hline Groups & Case nos. & $\begin{array}{c}\text { First day before } \\
\text { treatment }\end{array}$ & $\begin{array}{c}\text { First day } \\
\text { after treatment }\end{array}$ & $\begin{array}{c}\text { Seventh day } \\
\text { after treatment }\end{array}$ & P-value \\
\hline VD & 32 & $0.071 \pm 0.002$ & $1.017 \pm 0.035^{\mathrm{a}}$ & $1.233 \pm 0.417^{\mathrm{c}}$ & 0.002 \\
Control & 106 & $0.054 \pm 0.013$ & $0.065 \pm 0.021^{\mathrm{b}}$ & $0.072 \pm 0.011^{\mathrm{d}}$ & 0.231 \\
Healthy & 138 & $0.055 \pm 0.001$ & - & - & - \\
control & & & & &
\end{tabular}

${ }^{\mathrm{a} C o m p a r e d}$ with the control group, $\mathrm{P}<0.05$; ${ }^{\mathrm{b}}$ compared with the healthy control group, the difference was not statistically significant $(\mathrm{P}>0.05)$; ${ }^{\mathrm{c}}$ compared with the control group, $\mathrm{P}<0.05$; ${ }^{\mathrm{d}}$ compared with the healthy control group, the difference was not statistically significant $(\mathrm{P}>0.05)$. $\mathrm{VD}$, vascular dementia.

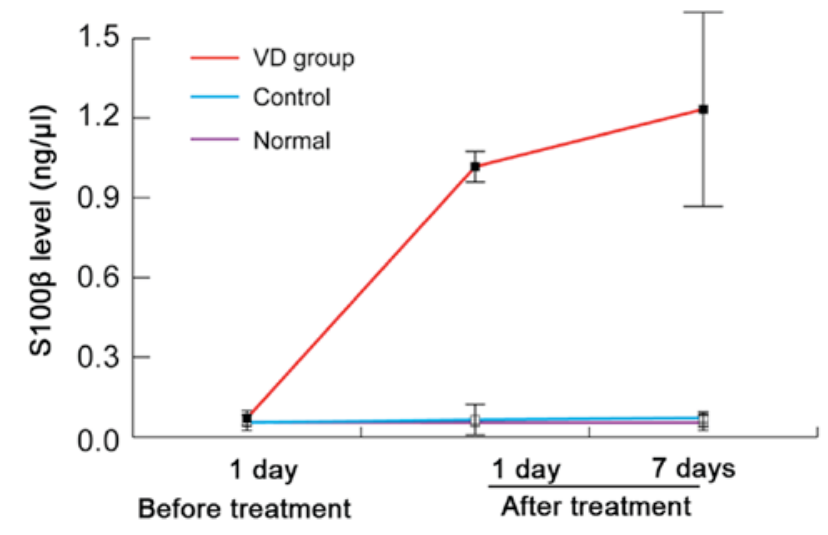

Figure 1. Measurement of the peripheral S100 $\beta$ levels of patients and those in the healthy control group through ELISA method (ng/ $\mu 1)$.

were significantly decreased compared to the control group; differences were statistically significant $(\mathrm{P}<0.05)$ (Table II).

Measurement of expression levels of the peripheral $S 100 \beta$ levels of patients and those in the healthy control group through the ELISA method $(\mathrm{ng} / \mathrm{ll}$ ). We tested the S100 $\beta$ levels of 138 patients with the basal ganglia hemorrhage in the experimental group and 138 cases of patients in the healthy control group. We discovered that the serum S100 $\beta$ levels of

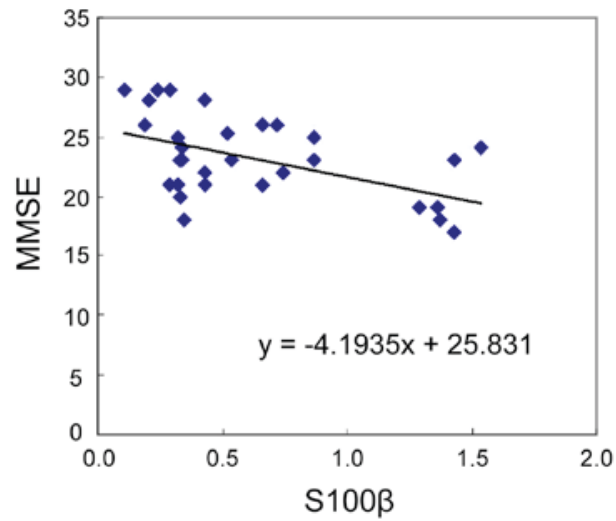

Figure 2. Correlation analysis of S100 $\beta$ protein and MMSE. MMSE, Mini-Mental State Examination.

VD patients were significantly higher than those in the control and healthy control groups; differences were statistically significant $(\mathrm{P}<0.05)$ (Table III and Fig. 1).

Correlation analysis between S100 $\beta$ and MMSE and MoCA scores. The correlation analysis was carried out with $\mathrm{S} 100 \beta$ as an independent variable and MAP, BMI, MMSE and MoCA scores as dependent variables. Our results suggest that $\mathrm{S} 100 \beta$ expression levels were negatively correlated to the 
Table IV. Correlation analysis (r) of S100 $\beta$ and clinical testing indicators.

\begin{tabular}{lcccccrr}
\hline Indicators & Gender & Age & MAP & BMI & Blood loss & MMSE & MoCA \\
\hline S100 $\beta$ & & & & & & & \\
r & 0.02 & 12.3 & 2.38 & -0.43 & 0.29 & -4.19 & -2.28 \\
P-value & $>0.05$ & $>0.05$ & $>0.05$ & $>0.05$ & $>0.05$ & $<0.05$ & $>0.05$ \\
\hline
\end{tabular}

MAP, mean arterial pressure; MMSE, Mini-Mental State Examination; MoCA, Montreal Cognitive Assessment.

Table V. Multiple linear regression analysis of S100 $\beta$ level influencing factors.

\begin{tabular}{|c|c|c|c|c|c|c|c|}
\hline \multirow[b]{2}{*}{ Variable } & \multirow[b]{2}{*}{$\beta$} & \multirow[b]{2}{*}{ SE } & \multirow[b]{2}{*}{$\beta^{\prime}$} & \multirow[b]{2}{*}{$\mathrm{t}$} & \multirow[b]{2}{*}{$\mathrm{P}$-value } & \multicolumn{2}{|c|}{$(95 \% \mathrm{CI})$} \\
\hline & & & & & & $\begin{array}{c}\text { Upper } \\
\text { limit }\end{array}$ & $\begin{array}{c}\text { Lower } \\
\text { limit }\end{array}$ \\
\hline MMSE & 0.531 & 0.14 & 0.764 & 0.412 & $<0.05$ & 0.26 & 0.81 \\
\hline
\end{tabular}

MMSE, Mini-Mental State Examination; CI, confidence interval.

Table VI. Comparison of operation situations and length of hospital stay between VD and control group.

\begin{tabular}{lccc}
\hline Groups & $\begin{array}{c}\text { Case } \\
\text { nos. }\end{array}$ & $\begin{array}{c}\text { Blood loss } \\
(\mathrm{ml})\end{array}$ & $\begin{array}{c}\text { Length of stay } \\
\text { (days) }\end{array}$ \\
\hline VD & 32 & $27.4 \pm 8.7$ & $23.4 \pm 2.8$ \\
Control & 106 & $29.6 \pm 3.2$ & $12.3 \pm 1.7$ \\
T-value & - & 0.49 & 19.5 \\
P-value & - & 0.48 & 0.012 \\
\hline
\end{tabular}

VD, vascular dementia.

MMSE score (rs=-4.19) and the difference was statistically significant $(\mathrm{P}<0.05)$, as shown in Table IV and Fig. 2. Multiple linear regression analysis of $\mathrm{S} 100 \beta$ level influencing factors is shown in Table V.

Comparison of operation situations and length of hospital stay between VD group and control group. In order to study the influence of VD on the clinical treatment of patients, we compared the treatment situations and postoperative lengths of stay between VD patients and the patients in the control group. We found that there were no significant differences with regards to blood loss of basal ganglia for patients in both groups $(\mathrm{P}>0.05)$; however, the length of stay of patients with VD had a significantly extended hospitalization time $(\mathrm{P}<0.05)($ Table VI).

\section{Discussion}

The cognitive ability and social behavior of patients with VD after basal ganglia hemorrhage are often decreased, and the disease course can last several months or even more than 6 months; therefore, it can seriously affect patients' response to treatment and quality of life (2). VD is one of the most common types of senile dementia, second only to Alzheimer's disease, accounting for about $10-50 \%$ of patients with dementia (8). With an ever increasing aging population and increasing incidence of cardiovascular and cerebrovascular diseases, the incidence of VD may become the most common type of dementia (9). Some studies have shown (8) that, among the elderly patients aged $\geq 75$ years, the incidence of VD after basal ganglia hemorrhage is higher, which may be correlated to the hemodynamic regulation ability and the central nervous system hypofunction of elderly patients.

S100 $\beta$ protein is a type of protein in nerve tissue, and under normal circumstances, the expression levels of S100 $\beta$ protein are significantly increased in glial and Schwann cells. Under physiological conditions, its level is very low in the serum. However, if the blood-brain barrier permeability is significantly increased due to damage to individual nerve cells or under various pathological conditions, the $S 100 \beta$ protein levels in the serum will be abnormally increased (10). Prohl et al (11) found that the $S 100 \beta$ protein levels in the serum on day 3 were significantly correlated to the neuropsychological assessment results in terms of the patients' learning, memory and executive function 6 months after the operation. In addition, in the past, in patients with Alzheimer's disease, glioma and hepatic encephalopathy, the phenomenon of the increase in the serum S100 $\beta$ level can be observed (12). However, these diseases have a similar pathological basis to the incidence of VD (13).

Our study found that, in the patients with VD after cerebral hemorrhage in basal ganglia, the expression levels of serum $\mathrm{S} 100 \beta$ are significantly higher than in patients without VD as well as the healthy control group; differences were statistically significant $(\mathrm{P}<0.05)$. We believed it may be due to the systemic or local inflammatory reaction caused by the basal ganglia hemorrhage, which changes the micro-thrombus quantity and cerebral perfusion quantity in the brain of patients and leads to oxidative stress injury; all of the above would cause neuronal cell dysfunction, thus releasing plenty of $\mathrm{S} 100 \beta$ proteins. In addition, long-term high blood pressure is also a high risk factor of VD, and the major pathophysiological changes of VD promoted by the hypertension can cause cerebral vascular sclerosis (14). Long-term high blood pressure can act directly on arterioles in the brain, such as on the perforating arteries at the brain base and the nearby central branch of basilar arteries, and it can easily lead to transparent steatosis in arterioles and form micro-aneurysms or micro-infarctions. In addition, longterm high blood pressure can also damage larger vascular 
endothelial cells by mechanical stimulation, thus resulting in atherosclerosis. Thus, it will lead to cerebral hemodynamic changes, which will further lead to the ischemia and anoxia of the local brain tissue and the nerve cell loss, eventually resulting in VD. Due to this pathology, VD may potentially be cured in some patients before the occurrence of the basal ganglia hemorrhage (15-18).

We discovered that VD can significantly prolong the postoperative length of stay and our findings were consistent with previous studies $(19,20)$. Our study found, in the serum of patients with early basal ganglia hemorrhage, a significant increase was found in the $S 100 \beta$ protein levels and it had great significance for an early diagnosis of VD and for the administration of appropriate treatment and prevention measures. However, the conclusions of the present study also need to be further supported by experiments in animal models and clinical tests of a larger sample size.

In conclusion, $\mathrm{S} 100 \beta$ protein has an important application value in early warning of VD and can be used as one of targets for diagnosis and treatment of VD after cerebral hemorrhage in the basal ganglion.

\section{References}

1. Black SE: Vascular cognitive impairment: epidemiology, subtypes, diagnosis and management. J R Coll Physicians Edinb 41: 49-56, 2011.

2. Guo J, Yang CX, Yang J and Yao Y: Glycyrrhizic acid ameliorates cognitive impairment on vascular dementia model rats associated with oxidative damage and inhibition of voltage-gated sodium channels. CNS Neurol Disord Drug Targets: May 27, 2016 (Epub ahead of print)

3. Zhi XL, Li CY, Xue M, Hu Y and Ji Y: Changes in cognitive function due to combined propofol and remifentanil treatment are associated with phosphorylation of Tau in the hippocampus, abnormal total water and calcium contents of the brain, and elevated serum S100 $\beta$ levels. Eur Rev Med Pharmacol Sci 20: 2156-2162, 2016.

4. Iemolo F, Sanzaro E, Duro G, Giordano A and Paciaroni M: The prognostic value of biomarkers in stroke. Immun Ageing 13: 19, 2016.

5. Román GC, Tatemichi TK, Erkinjuntti T, Cummings JL, Masdeu JC, Garcia JH, Amaducci L, Orgogozo JM, Brun A, Hofman A, et al: Vascular dementia: diagnostic criteria for research studies. Report of the NINDS-AIREN International Workshop. Neurology 43: 250-260, 1993.

6. Ong HL, Subramaniam M, Abdin E, Wang P, Vaingankar JA, Lee SP, Shafie S, Seow E and Chong SA: Performance of Mini-Mental State Examination (MMSE) in long-stay patients with schizophrenia or schizoaffective disorders in a psychiatric institute. Psychiatry Res 241: 256-262, 2016.
7. Marceau EM, Lunn J, Berry J, Kelly PJ and Solowij N: The Montreal Cognitive Assessment (MoCA) is sensitive to head injury and cognitive impairment in a residential alcohol and other drug therapeutic community. J Subst Abuse Treat 66: 30-36, 2016.

8. Wen $\mathrm{YH}, \mathrm{Wu}$ SS, Lin $\mathrm{CH}$, Tsai JH, Yang P, Chang YP and Tseng KH: A bayesian approach to identifying new risk factors for dementia: a nationwide population-based study. Medicine (Baltimore) 95: e3658, 2016.

9. Du SQ, Wang XR, Xiao LY, Tu JF, Zhu W, He T and Liu CZ: Molecular mechanisms of vascular dementia: what can be learned from animal models of chronic cerebral hypoperfusion? Mol Neurobiol: May 20, 2016 (Epub ahead of print).

10. Zhou S, Bao J, Wang Y and Pan S: S100 $\beta$ as a biomarker for differential diagnosis of intracerebral hemorrhage and ischemic stroke. Neurol Res 38: 327-332, 2016.

11. Prohl J, Bodenburg S and Rustenbach SJ: Early prediction of long-term cognitive impairment after cardiac arrest. J Int Neuropsychol Soc 15: 344-353, 2009.

12. Scott DA, Evered LA and Silbert BS: Cardiac surgery, the brain, and inflammation. J Extra Corpor Technol 46: 15-22, 2014.

13. Quintard H, Leduc S, Ferrari P, Petit I and Ichai C: Early and persistent high level of PS $100 \beta$ is associated with increased poor neurological outcome in patients with SAH: is there a PS $100 \beta$ threshold for SAH prognosis? Crit Care 20: 33, 2016.

14. Chou RH, Chiu CC, Huang CC, Chan WL, Huang PH, Chen YC, Chen TJ, Chung CM, Lin SJ, Chen JW, et al: Prediction of vascular dementia and Alzheimer's disease in patients with atrial fibrillation or atrial flutter using $\mathrm{CHADS}_{2}$ score. J Chin Med Assoc 79: 470-476, 2016.

15. Lee C: Best linear unbiased prediction of individual polygenic susceptibility to sporadic vascular dementia. J Alzheimers Dis 53: 1115-1119, 2016

16. Min D and Xu-Feng W: An updated meta-analysis of the efficacy and safety of acupuncture treatment for vascular cognitive impairment without dementia. Curr Neurovasc Res 13: 230-238, 2016

17. Yang L, Jin X, Yan J, Jin Y, Yu W, Wu H and Xu S: Prevalence of dementia, cognitive status and associated risk factors among elderly of Zhejiang province, China in 2014. Age Ageing: May 21, 2016 (Epub ahead of print).

18. Czuriga-Kovács KR, Czuriga D and Csiba L: Influence of hypertension, alone and in combination with other vascular risk factors on cognition. CNS Neurol Disord Drug Targets 15: 690-698, 2016.

19. Lane EM, Paul RH, Moser DJ, Fletcher TD and Cohen RA: Influence of education on subcortical hyperintensities and global cognitive status in vascular dementia. J Int Neuropsychol Soc 17: 531-536, 2011.

20. Plassman BL, Langa KM, Fisher GG, Heeringa SG, Weir DR, Ofstedal MB, Burke JR, Hurd MD, Potter GG, Rodgers WL, et al: Prevalence of dementia in the United States: the aging, demographics, and memory study. Neuroepidemiology 29: 125-132, 2007. 